\title{
Potentiometric determination of piroxicam and oxfendazole in pharmaceuticals
}

\author{
Nagaraju Rajendraprasad $^{\mathrm{a}^{*}}$ and Kanakapura Basavaiah ${ }^{\mathrm{b}}$
}

${ }^{a}$ PG Department of Chemistry, JSS College of Arts, Commerce and Science, Ooty Road, Mysore-570 025, Karnataka, India ${ }^{b}$ Department of Studies in Chemistry, Manasagangothri, University of Mysore, Mysore-570 006, Karnataka, India

\section{H R O N I C L EA B S T R A C T}

Article history:

Received March 21, 2015

Received in revised form

June 29, 2015

Accepted 11 September 2015

Available online

7 October 2015

Keywords:

Piroxicam

Oxfendazole

Potentiometry

Pharmaceuticals

Development

Validation

\begin{abstract}
Piroxicam (POC) and oxfendazole (OFA) are two widely used veterinary non-steroidal antiinflammatory and anthelmintic medicines, respectively. Simple, precise and accurate and costeffective methods for the determination of POC and OFZ in bulk drug and in its dosage forms have been developed and validated. The methods are based on the potentiometric titration of compound with acetous perchloric acid in glacial acetic acid medium using modified glasssaturated calomel electrode system. The methods are applicable over the ranges 1.5 - $15 \mathrm{mg}$ and 7.5-15 mg, for POC and OFA, respectively. The proposed methods were successfully applied to the determination of active substances in their pharmaceutical dosage forms. A statistical comparison was made on the results of proposed methods with those obtained for reference method. The intra-day and inter-day precision and accuracy values obtained were satisfactory with RSD and RE values less than 3\%. Excipients in tablets did not interfere to the assay as shown by the recovery study via standard addition technique with mean percentage recoveries in the range $97.8-100.6 \%$.
\end{abstract}

\section{Introduction}

Piroxicam (POC) and oxfendazole (OFA), chemically known as 4-hydroxy-2-methyl-N-(pyridine2-yl)-2H-1,2-benzothiazine-3-carbox-amide-1,1-dioxide (Figure 1a) and methyl-N-[6(benzenesulfinyl)-1H-1,3-benzodiazol-2-yl]carbamate (Figure 1b), respectively, are two commonly used veterinary anti-inflammatory and anthelmintic drugs. POC has been shown to be an effective analgesic in fracture, dental, postoperative and postpartum pain. The pharmacological actions of these oxicams are related to inhibition of cyclooxygenase (Cox), a key enzyme of prostaglandine biosynthesis at the site of inflammation. ${ }^{1}$ OFA, a fenbendazole sulfoxide's main metabolite, is used for protecting livestock against roundworm, strongyles and pinworms. ${ }^{2}$

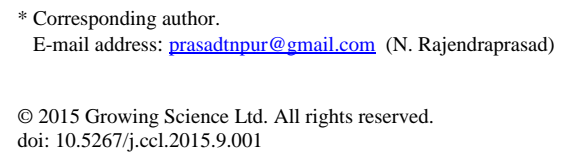


<smiles>CN1C(C(=O)Nc2ccccn2)=C(O)c2ccccc2S1(=O)=O</smiles>

Fig. 1a. Structure of POC

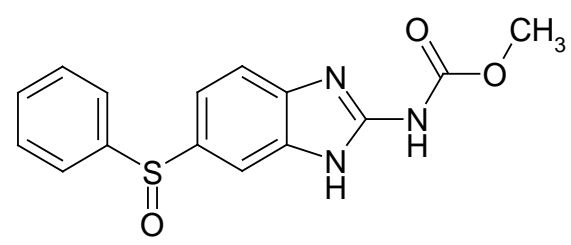

Fig. 1b. Structure of OFA

Vast research is in progress to discover new drugs since many decades. Due to their inherent use many therapeutically active compounds are synthesized and hence simple quantification assay procedures are most required. POC and OFA are two commonly used therapeutics and hence simple, rapid, accurate, precise and selective procedures are required to quantify or assaying them in their pure form and in dosage forms.

Various methods have been reported for the assay of POC in both pharmaceuticals and in body fluids. These include polarographic ${ }^{3}$, capillary zone electrophoretic ${ }^{4}$, chromatographic $^{5-11}$, spectrofluorimetric $^{12,13}$ and spectrophotometric methods ${ }^{14-20}$. In the polarographic method ${ }^{3}$ carbonpaste electrode was used to perform the electrolysis in $0.05 \mathrm{M} \mathrm{H}_{2} \mathrm{SO}_{4}$ and buffers of $\mathrm{pH} 6$ and 11 media. The capillary zone electrophoretic method ${ }^{4}$ POC was quantified in dragees, suspension, suppositories, capsules, injection solutions and tablets but not validated properly. The reported chromatographic ${ }^{5-11}$ and fluorimetric methods ${ }^{12,13}$ are most specific for the assay of POC. However, they have demerits like sample clean up, sample pre-treatment, instrumental limitations and need of expensive instrument and skillful operator. Hence, these methods cannot be used for routine analytical work. In the spectrophotometric method reported by El-Didamony and Amin ${ }^{14}$ POC was quantified by redox reaction using iron(III) and o-phenanthroline. After the oxidation of POC was completed resulted iron(II) was treated with o-phenanthroline and obtained ferroin complex was measured at $510 \mathrm{~nm}$ at $\mathrm{pH}$ 4.8. Gowda et $\mathrm{al}^{15}$ was proposed an indirect procedure which involves the oxidation of POC with cerium(IV), treatment of excess cerium with methdilazine hydrochloride and measurement of redcolored product. The flow injection spectrometric method ${ }^{16}$ is based on the oxidation of POC by a known excess of N-bromosuccinimide in an acidic medium, followed by a reaction of excess oxidant with chloranilic acid to bleach its purple color. The basis of El-Riesa method ${ }^{17}$ is measurement of a 1:2 yellow coloured chromogen between POC and uranyl acetate at $395 \mathrm{~nm}$. Sastry et al ${ }^{18}$ proposed in his method that to utilization of Sevron blue 5G dye as an ion-pairing reagent. The method is based on the measurement of the absorbance of the chloroform extract of the ion-association complex formed between the drug and the dye at $\mathrm{pH}$ 7.0. A differential spectrophotometric method was developed by Rao et al. ${ }^{19}$ The methanolic extract of POC was measured at $326 \mathrm{~nm}$. In Wang's ${ }^{20}$ ultra-violet spectrophotometric method POC was dissolved in $0.1 \mathrm{M}$ methanolic $\mathrm{HCl}$ and the absorbance was measured at $334 \mathrm{~nm}$.

Chromatographic ${ }^{21-27}$ and radioimmunoassay ${ }^{28}$ were devoted by different researchers for assaying OFA in biological materials like serum, milk, muscle and plasma. OFA was assayed before by ratiospectra derivative spectrophotometric, ${ }^{29}$ chemometric calibration ${ }^{30}$ and the continuous wavelet transform $^{31}$ techniques in pharmaceuticals.

Though the reported spectrophotometric methods are selective for the assay of POC, they found limited application due to multistep and incomplete reactions, ${ }^{14-16}$ use of hazardous and radioactive substance, ${ }^{17}$ extraction steps and maintenance of stringent experimental conditions, ${ }^{18}$ and measurement of absorbance at lower wavelengths ${ }^{19,20}$ which is a source of photometric error.

For the assay of OFA the reported methods are not suitable to use as quality control procedures because several graphical and separation assumptions are required to be considered. Besides the reported chemometric calibration ${ }^{30}$ and the continuous wavelet transform ${ }^{31}$ techniques are applicable for assaying OFA in the presence of oxyclozanide. 
Therefore, simple, rapid, precise and accurate, selective and cost-effective methods are required to determine POC and OFA in pure form and in dosage forms.

Potentiometric method with glass electrode can provide very accurate and sharp end points, valuable and straightforward means of assaying drug in pharmaceutical formulations because of the possibility to determine directly the active basic nitrogen containing moiety using low-cost, instrument. Simplicity, speed, compatibility and adequacy of assay procedure make the technique very attractive for the assay of pharmaceutical products.

POC and OFA are official in European Pharmacopoeia (EP) ${ }^{32}$ and United States Pharmacopoeia $(\mathrm{UP})^{33}$, respectively. Both have been quantified by non aqueous titrimetric procedures and potentiometric end point location. For each compounds the assay was performed by titrating glacial acetic acid-acetic anhydride solution of POC or formic acid and acetic anhydride solution of OFA with $0.1 \mathrm{~N}$ perchloric acid. These procedures involve usage of laboratory incompatible and hazardous anhydride and require $250 \mathrm{mg}$ of POC or $300 \mathrm{mg}$ of OFA for each titration. Hence, this is applicable for the assay in macro size samples.

Hence a smart attempt has been made to develop two simple, rapid, selective, precise and accurate, and economic methods for the assay of POC and OFA in pure and dosage forms at semi-micro level. The methods are validated according to the current ICH guidelines. ${ }^{34}$

\section{Experimental}

\subsection{Apparatus}

Elico 120 digital pH meter (Ahmedabad, India) provided with a combined glass-SCE electrode system was used to perform potentiometric titration. The $\mathrm{KCl}$ of the salt bridge was replaced by saturated solution of $\mathrm{KCl}$ in glacial acetic acid.

\subsection{Reagents and materials}

All chemicals used were of analytical reagent grade. All solutions were made in glacial acetic acid unless mentioned otherwise in titrimetric methods. The pure POC and OFA (both 99.8\% pure) were kindly provided by Cipla India Ltd, Mumbai, India, received as gift and it was used. Pirox-DT and Suganril (both from Cipla India Ltd, Mumbai, India) POC tablets and OFA Bolus [Pharmanza (India) Pvt, Ltd] were purchased from local commercial sources.

A stock solution of ( 0.1 M) perchloric acid (Merck Specialties Pvt, Ltd Mumbai, India) was diluted appropriately with glacial acetic acid to get a working solution of $5 \mathrm{mM}$ and it was standardized before use. ${ }^{35}$

\subsection{Standard drug solutions for assay}

Standard solution containing $1.5 \mathrm{mg} \mathrm{mL}^{-1}$ POC or OFA were prepared by dissolving $150 \mathrm{mg}$ of pure substance in glacial acetic acid and diluting to the mark in a $100 \mathrm{ml}$ calibrated flask with the same solvent.

\subsection{General procedures}

Aliquots of the standard drug solutions equivalent to 1.5 - $15 \mathrm{mg}$ of POC or 7.5-15 $\mathrm{mg}$ of OFA was accurately measured by means of burette and transferred into a dry $100 \mathrm{ml}$ beaker. The solution 
was diluted to $20 \mathrm{ml}$ with glacial acetic acid. Glass membrane electrode [the combined glass-SCE (modified)] was immersed into the solution. The content was titrated with standard $5 \mathrm{mM} \mathrm{HClO}_{4}$ on magnetic stirrer. Near the equivalence point, titrant was added in $0.1 \mathrm{ml}$ increments. After each addition of titrant, the solution was stirred for 20-30 s and the steady potential was noted. The addition of titrant was continued until there was no significant change in potential on further addition of titrant. The equivalence point volume was determined using titration curves (Fig. 2a and 2b). The amount of drug in the measured aliquot was calculated by using the Eq. (1) as follows,:

$$
M_{o}=\frac{[V C]_{\mathrm{HClO}_{4}} M}{n},
$$

where $\mathrm{M}_{\mathrm{o}}$ is amount in milligrams of compound (relative molecular mass $\mathrm{M}$ ) titrated with $\mathrm{V} \mathrm{ml}$ of $\mathrm{C}$ molar $\mathrm{HClO}_{4}$. The number of moles perchloric acid reacting with each mole of the compound is denoted by $n$.

\subsection{Procedure for tablets}

Twenty tablets were weighed and pulverized. The powder equivalent to 150mg of POC/OFA was transferred into a $100 \mathrm{ml}$ calibrated flask. The content was shaken with $70 \mathrm{ml}$ of glacial acetic acid for about $20 \mathrm{~min}$, the volume was made upto the mark with glacial acetic acid, mixed well and filtered using Whatmann No 42 filter paper. The first $10 \mathrm{ml}$ portion of the filtrate was rejected and then a suitable aliquot (say $10 \mathrm{ml}$ ) was next subjected to analysis by the recommended procedure described above.

\section{Results and discussion}

POC and OFA are containing nitrogenous functional groups in their structure. The basic property of these compounds was enhanced due to the leveling effect of glacial acetic acid and titrated with perchloric acid. A steep rise in the potential was observed at the equivalence point with potentiometric end point detection (Fig. 2). A reaction stoichiometry of 1:1 between the titrated drug and titrant was obtained which served as the basis for calculation. Using $5 \mathrm{mM}$ perchloric acid, $1.5-15 \mathrm{mg}$ of POC or 7.5-15 mg of OFA was conveniently determined. Since this reaction is simply neutralization one, the relationship between the drug amount and the titration end point was correlated with potential difference. The equivalence point was determined by applying the graphical method (Figure 2). The reaction between POC/OFA and perchloric acid was found stoichiometric in the ratio 1:1 for the range of drug studied. The linear relationship between the drug and titrant was verified by the method of least squares. In which the regression coefficient values between the amounts of drug titrated and volume of titrant were found to be 0.9975 and 0.9889 , for POC and OFA, respectively. The calibration plots showing the linear relationship between the quantities of drug titrated and volume of perchloric acid added are presented for both methods in Fig. 3. The following reaction scheme (1-4) is postulated for the neutralization of POC/OFA $\left(\mathrm{R}_{3} \mathrm{~N}\right)$ with $\mathrm{HClO}_{4}$ in acetic acid medium.

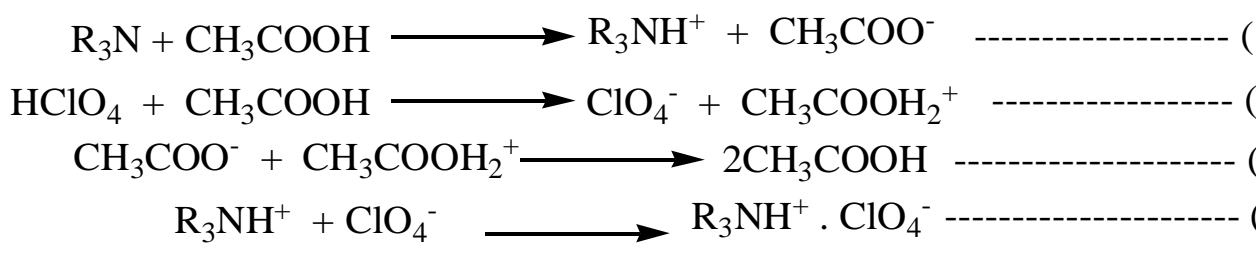




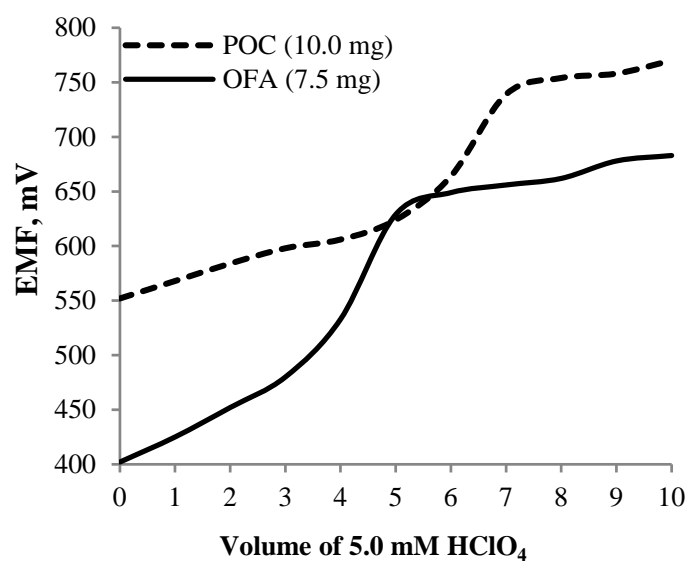

(a)

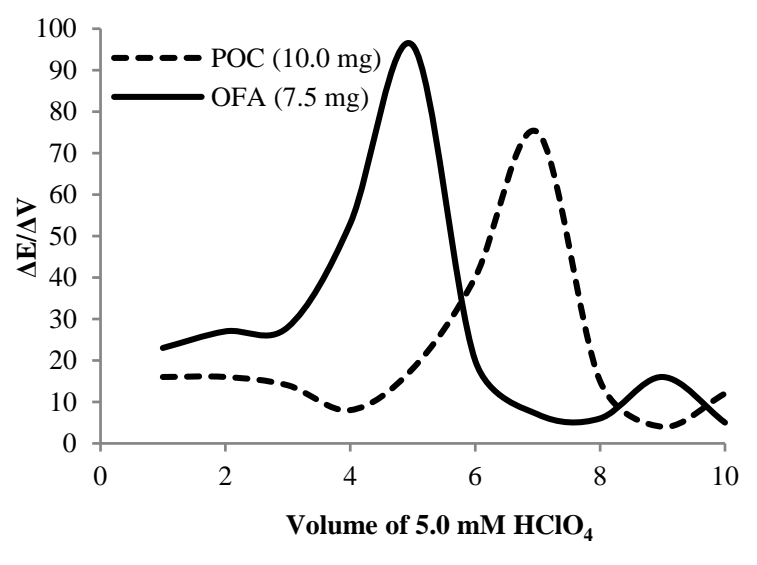

(b)

Fig. 2. (a) Normal titration curve and (b) First derivative titration curve
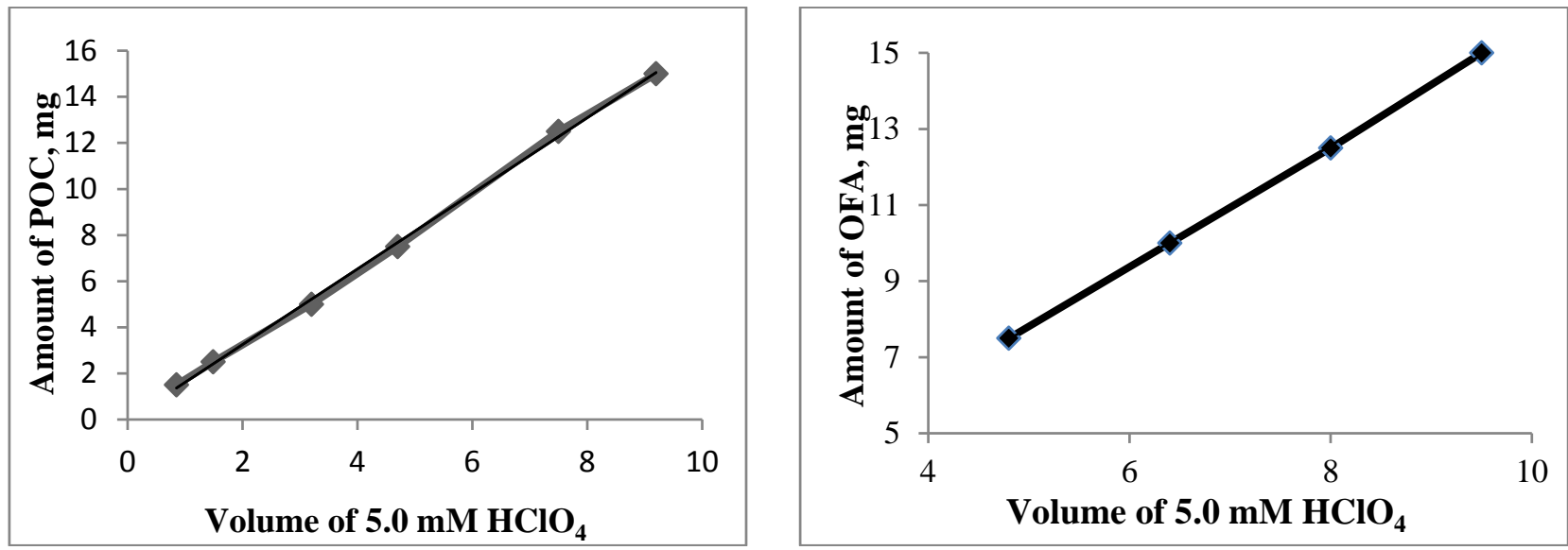

Fig. 3. Calibration plots showing the linear relationship between volume of $\mathrm{HClO}_{4}$ consumed and amount of drug taken for titration

\subsection{Validation of procedures}

\subsubsection{Accuracy and precision}

The accuracy and precision of the methods were checked on intra-day and inter-day basis. Three different amounts of drug within the range of study were subjected to analysis in seven and five replicates during the same day and five consecutive days. The inter-day or between- day precision of the proposed methods was performed in triplicate and for the amounts found the pooled-standard deviation was calculated. The RSD values of intra-day and inter-day studies for POC/OFA showed that the excellent precision of the methods (Table 1). The accuracy of each method was determined by the percent mean deviation from known concentration by using the Eq. (2) given as follows,

$$
\% R E=\frac{D_{F}-D_{T}}{D_{T}} \times 100,
$$

where $\mathrm{D}_{\mathrm{F}}$ is milligrams of POC/OFA found and $\mathrm{D}_{\mathrm{T}}$ is milligrams of POC/OFA subjected to assay. The calculated intra- and inter-day RE values were found in the range from 0.26 to 3.6\%, and this revealed that the methods are accurate enough. These results are presented in Table 1. 
Table 1. Accuracy and precision evaluation

\begin{tabular}{ccccccccc}
\hline $\begin{array}{c}\text { Accuracy } \\
\text { and precision }\end{array}$ & $\begin{array}{c}\text { POC } \\
\text { Taken, } \\
\mathrm{mg}\end{array}$ & $\begin{array}{c}\text { POC } \\
\text { Found } \\
\mathrm{mg}\end{array}$ & $\begin{array}{c}\text { RE, } \\
\%\end{array}$ & $\begin{array}{c}\text { RSD, } \\
\%\end{array}$ & $\begin{array}{c}\text { OFA Taken, } \\
\mathrm{mg}\end{array}$ & $\begin{array}{c}\text { OFA } \\
\text { Found }, \mathrm{mg}\end{array}$ & $\begin{array}{c}\text { RE, } \\
\%\end{array}$ & $\begin{array}{c}\text { RSD, } \\
\%\end{array}$ \\
\hline \multirow{2}{*}{ Intra-day } & 3.0 & 3.05 & 1.67 & 1.98 & 7.50 & 7.47 & 0.40 & 0.69 \\
$(\mathrm{n}=7)$ & 6.0 & 6.11 & 1.83 & 2.11 & 10.0 & 10.04 & 0.40 & 0.89 \\
& 9.0 & 9.20 & 2.22 & 1.11 & 15.0 & 15.04 & 0.26 & 0.54 \\
\hline \multirow{2}{*}{ Inter-day } & 3.0 & 3.02 & 0.60 & 1.85 & 7.50 & 7.24 & 3.20 & 1.17 \\
$(\mathrm{n}=5)$ & 6.0 & 6.10 & 1.67 & 1.73 & 10.0 & 10.07 & 0.70 & 2.21 \\
& 9.0 & 8.86 & 1.55 & 1.26 & 15.0 & 14.46 & 3.60 & 3.86 \\
\hline
\end{tabular}

*Mean value of n determinations

\subsubsection{Ruggedness of the method}

Method ruggedness was evaluated by performing the assay by four different analysts as well as using four different burettes. The inter-analysts RSD values lesser than $3 \%$ whereas the inter-burettes RSD for the same POC/OFA amounts was less than about $2 \%$ suggesting that the developed methods were rugged. These results are shown in Table 2.

\subsubsection{Application}

The proposed potentiometric procedures were applied to the determination of POC/OFA in their tablets. The results were statistically compared with those obtained using official $\mathrm{EP}^{33}$ and $\mathrm{UP}^{34}$ methods for POC and OFA, respectively. The results of the proposed methods are satisfactory when compared with those of Pharmacopeial methods and also with the label claimed. The results were compared statistically by Student's $t$-test for accuracy and by variance $F$-test for precision ${ }^{36}$ with those of the reference method at $95 \%$ confidence level. These data are summarized in Table 3 . The calculated $t$-and $F$-values did not exceed the critical values at $95 \%$ confidence level for taken degrees of freedom which inferring that proposed methods are accurate and precise enough.

\subsubsection{Recovery study}

A standard addition procedure was adopted for the assessment of recovery experiments. This was done by spiking of a fixed amount of pre-analyzed drug from formulation into pure drug at three different levels, and the total was found by the proposed methods. The assay performance was checked in three replicates for each level of drug. The results, as compiled in Table 4, showed that recovery of pure drug were in the range from 98.33 to $102 \%$, indicating that the excipients in tablets did not interfere to the assay.

Table 2. Method ruggedness expressed as intermediate precision (\% RSD)

\begin{tabular}{ccccc}
\hline Variation & $\begin{array}{c}\text { POC Taken, } \\
\text { mg }\end{array}$ & $\begin{array}{c}\text { RSD, } \\
\%\end{array}$ & OFA Taken, mg & $\begin{array}{c}\text { RSD, } \\
\%\end{array}$ \\
\hline \multirow{2}{*}{ Inter-analyst } & 3.0 & 1.98 & 7.50 & 1.69 \\
$(\mathrm{n}=4)$ & 6.0 & 1.76 & 10.0 & 1.09 \\
& 9.0 & 1.21 & 15.0 & 1.33 \\
\hline Inter-burette & 3.0 & 1.78 & 7.50 & 0.70 \\
$(\mathrm{n}=4)$ & 6.0 & 0.98 & 10.0 & 1.56 \\
& 9.0 & 1.22 & 15.0 & 1.88 \\
\hline
\end{tabular}

\section{Conclusion}

Simple, rapid, cost-effective and rugged methods were developed and validated for the determination of piroxicam and oxfendazole in their pure form and in tablets. The proposed methods 
are more selective for the assay of POC and OFA in pure form and in dosage forms because they do not involve multistep or incomplete reactions, usage of hazardous and radioactive substance, extraction steps, maintenance of stringent experimental conditions, and measurement of absorbance at lower wavelengths. No theoretical assumptions involved in the calculation. The proposed methods could be successfully applied to the determination of $1.5-15 \mathrm{mg}$ of POC or 7.5-15 mg of OFA using $5 \mathrm{mM}$ solution of perchloric acid. Considering the results obtained, it is possible to assert that the methods are rapid, selective, both accurate and precise and hence suitable for the determination of drugs under investigation in their dosage forms. The proposed methods have the distinct advantages over the existing methods in terms of simplicity of technique and ease of performance and do not need expensive and highly sophisticated equipment or high-cost organic solvents which are required for HPLC analysis reported earlier. Hence, the methods can be adopted as routine analytical procedures in pharmaceutical quality control laboratories.

Table 3. Results of analysis of POC tablets and OFA bolus by the proposed methods and comparison of results with the reference method

\begin{tabular}{|c|c|c|c|c|c|c|c|c|c|}
\hline \multirow[b]{2}{*}{ Tablets } & \multirow{2}{*}{$\begin{array}{c}\text { Label claim, } \\
\text { mg/tablet }\end{array}$} & \multicolumn{3}{|c|}{ Reference Method } & \multicolumn{3}{|c|}{ Proposed method } & \multirow{2}{*}{$\begin{array}{c}\boldsymbol{F} \text { - } \\
\text { Value }\end{array}$} & \multirow{2}{*}{$t$ - Value } \\
\hline & & \%Found ${ }^{*}$ & $\begin{array}{c}\text { Standard } \\
\text { deviation (S) }\end{array}$ & $\begin{array}{c}\text { Variance } \\
\left(\mathrm{S}^{2}\right)\end{array}$ & \%Found ${ }^{*}$ & $\begin{array}{c}\text { Standard } \\
\text { deviation (S) }\end{array}$ & $\begin{array}{c}\text { Variance } \\
\left(\mathrm{S}^{2}\right)\end{array}$ & & \\
\hline Pirox-DT & 20 & 101.3 & 0.85 & 0.7225 & 102.8 & 0.96 & 0.9216 & 1.28 & 2.62 \\
\hline $\begin{array}{l}\text { OFA- } \\
\text { Bolus }\end{array}$ & 2200 & 99.1 & 1.68 & 2.8224 & 97.34 & 1.32 & 1.7424 & 1.63 & 1.85 \\
\hline
\end{tabular}

*Mean value of five determinations

Tabulated t- and F- values at the $95 \%$ confidence level and for four degrees of freedom are 2.77 and 6.39, respectively.

\section{Acknowledgement}

Authors wish to thank Cipla India Ltd, Mumbai, India, for providing pure piroxicam and oxfendazole pure samples for analysis. The author (NRP) is very grateful to authorities of JSS Mahavidyapeetha for providing facilities to pursue this research work.

Table 4. Results of recovery study

\begin{tabular}{|c|c|c|c|c|c|c|c|c|c|}
\hline \multicolumn{5}{|c|}{ POC } & \multicolumn{5}{|c|}{$\overline{\text { OFA }}$} \\
\hline $\begin{array}{l}\text { Tablet } \\
\text { Studied }\end{array}$ & $\begin{array}{c}\text { POC in } \\
\text { tablet } \\
\text { extract, } \\
\text { mg }\end{array}$ & $\begin{array}{c}\text { Amount } \\
\text { of pure } \\
\text { POC } \\
\text { added, } \\
\text { mg }\end{array}$ & $\begin{array}{l}\text { Total } \\
\text { POC } \\
\text { found, } \\
\text { mg }\end{array}$ & $\begin{array}{c}\text { Pure POC } \\
\text { recovered }^{*} \\
\%\end{array}$ & $\begin{array}{l}\text { Tablet } \\
\text { Studied }\end{array}$ & $\begin{array}{c}\text { OFA } \\
\text { in Bolus } \\
\text { extract, } \\
\text { mg }\end{array}$ & $\begin{array}{c}\text { Amount } \\
\text { of pure } \\
\text { OFA } \\
\text { added, } \\
\text { mg }\end{array}$ & $\begin{array}{l}\text { Total } \\
\text { OFA } \\
\text { found, } \\
\text { mg }\end{array}$ & $\begin{array}{c}\text { Pure } \\
\text { OFA } \\
\text { Recovered* }^{*} \\
\%\end{array}$ \\
\hline \multirow{3}{*}{ Suganaril } & 4.0 & 2.0 & 6.04 & $102.0 \pm 0.63$ & \multirow{3}{*}{$\begin{array}{c}\text { OFA } \\
\text { Bolus }\end{array}$} & 3.0 & 3.0 & 5.99 & $99.57 \pm 0.15$ \\
\hline & 4.0 & 4.0 & 8.05 & $101.3 \pm 0.72$ & & 3.0 & 6.0 & 8.95 & $98.33 \pm 0.17$ \\
\hline & 4.0 & 6.0 & 9.99 & $99.80 \pm 1.12$ & & 3.0 & 9.0 & 11.97 & $99.00 \pm 0.09$ \\
\hline
\end{tabular}




\section{References}

1. Mammen, L., Schmidt, C.P. (1995). Photosensitivity reactions: a case report involving NSAIDs. American Family Physician, 52 (2) 575-579.

2. http://www.chemicalland21.com/lifescience/phar/OXFENDAZOLE.htm.

3. Vire, J-C., Kauffman, J-M., Braun, J., Patriarche, G. J. (1985). Analytical study of piroxicam. Journal De Pharmacie De Belgique, 40 (3) 133-138.

4. Donato, M. G., Baeyens, W., Van Den Bossche, W., Sandra, P. (1994). The determination of non-steroidal anti-inflammatory drugs in pharmaceuticals by capillary zone electrophoresis and micellar electrokinetic capillary chromatography. Journal of Pharmaceutical and Biomedical Analysis, 12 (1) 21-26.

5. Dadashzadeh, S., Vali, A. M., Rezagholi N. J. (2002). LC determination of piroxicam in human plasma. Journal of Pharmaceutical and Biomedical Analysis, 28 (6) 1201- 1204.

6. Doliwa, A., Santoyo, S., Campanero, M. A., Ygartua, P. (2001). Sensitive LC determination of piroxicam after in vitro transdermal permeation studies. Journal of Pharmaceutical and Biomedical Analysis, 26 (4) 531- 537.

7. Ji, H.Y., Lee, H. W., Kim, Y. H., Jeong, D. W., Lee, H. S. (2005). Simultaneous determination of piroxicam, meloxicam and tenoxicam in human plasma by liquid chromatography with tandem mass spectrometry. Journal of Chromatography B, 826 (1-2) 214- 219.

8. Amanlou, M., Dehpour, A. R. (1997). Rapid method for the determination of piroxicam in rat plasma using high-performance liquid chromatography. Journal of Chromatography B: Biomedical Sciences and Applications, 696 (2) 317-319.

9. Basan, H, Göğer, N. G., Ertaş, N., Orbey M. T. (2001). Quantitative determination of piroxicam in a new formulation (piroxicam-beta-cyclodextrin) by derivative UV spectrophotometric method and HPLC. Journal of Pharmaceutical and Biomedical Analysis, 26 (2) 171-178.

10. Starek, M., Krzek, J., Tarsa, M., Żylewski, M. (2009). Determination of piroxicam and degradation products in drugs by TLC. Chromatographia, 69 (3-4) 351-356.

11. Savaşer, A., Karataş, A., Özkan, Y., Yüksel, N., Özkan, S. A., Baykara, T. (2004). Validated LC determination of the piroxicam- $\beta$-cyclodextrin inclusion complex in tablets and in human plasma. Chromatographia, 59 (9-10) 555-560.

12. Escandar, G. M., Bystol, A. J., Campiglia, A. D. (2002). Spectrofluorimetric method for the determination of piroxicam and pyridoxine. Analytica Chimica Acta, 466 (2) 275-283.

13. Damiani, P. C., Bearzotti, M., Cabezón, M., Olivieri, A. C. (1998). Spectrofluorometric determination of piroxicam. Journal of Pharmaceutical and Biomedical Analysis, 17 (2) 233236. 
14. Amin, A. S., El-Didamony, A. M. (2004). Adaptation of a color reaction for spectrophotometric determination of diclofenac sodium and piroxicam in pure form and in pharmaceutical formulations. Analytical Letters, 37 (6) 1151-1162.

15. Gowda, B. G., Seetharamappa, J., Melwanki, M. B. (2002). Indirect spectrophotometric determination of propanalol hydrochloride and piroxicam in pure and pharmaceutical formulations. Analytical Sciences, 18 (6) 671- 674.

16. Al-Momani, I. F. (2006). Indirect flow-injection spectrophotometric determination of meloxicam, tenoxicam and piroxicam in pharmaceutical formulations. Analytical Sciences, 22 (12) 1611- 1614.

17. El-Ries, M. A. (1998). Spectrophotometric determination of piroxicam and tenoxicam in pharmaceutical preparations using uranyl acetate as a chromogenic agent. Analytical Letters, 31 (5) 793-807.

18. Sastry, C. S. P., Rama Srinivas, K., Krishna Prasad, K. M. M. (1996). Sevron blue 5G as an ion-pairing reagent for the determination of acidic drugs in pharmaceutical formulations. Indian Journal of Pharmaceutical Sciences, 58 (3) 120-122.

19. Rao, B. E., Raghuveer, S., Srivastav, C. M. R., Vatsa, D. K. (1993). Spectrophotometric determination of piroxicam in capsules and tablets. Indian Drugs, 30 (4) 194-197.

20. Wang, G. (1989). Ultra-violet spectrophotometric determination of piroxicam in tablets. Yaowu Fenxi Zazhi, 9 (3) 189-190.

21. Tsina, I. W., Matin, S. B. (1981). Determination of oxfendazole in cow milk by reversed-phase high-performance liquid chromatography. Journal of Pharmaceutical Sciences, 70 (8) 858-60.

22. Shah, G., Bradley, D., Shek, E. (1984). Liquid chromatographic determination of oxfendazole in swine feeds. Journal of the Association of Official Analytical Chemists, 67 (4) 707-714.

23. Blanchflower, W. J., Cannavan, A., Kennedy, D. G. (1994). Determination of fenbendazole and oxfendazole in liver and muscle using liquid chromatography-mass spectrometry. Analyst, 119 (6)1325-1328.

24. Su, S-C., Chou, H-H., Chang, P-C., Liu, C-H., Chou, S-S. (2004). Oxfendazole and oxfendazole sulfone in livestock by matrix solid phase dispersion extraction technique and HPLC. Journal of Food and Drug Analysis, 12 (3) 244-253.

25. Dimitrios, S. N., Nickos, A. B., Ioannis, E. P. (1994). Ion-Pair isolation and liquid chromatographic determination of albendazole, oxfendazole, oxibendazole, and thiabendazole residues in milk. Journal of Liquid Chromatography, 17 (19) 4145-4155

26. Lucie, H., Ivana, B., Dalibor, Š., Ludmila, M., Alena, L., Zdeněk, O., Petr, S. (2012). Optimisation of an HPLC method for the simultaneous determination of pyrantel pamoate, 
praziquantel, fenbendazole, oxfendazole and butylhydroxyanisole using a phenyl stationary phase. Analytical Methods, 4 (6) 1592-1597

27. LeVan, L. W., Barnes C. J. (1991). Liquid chromatographic method for multiresidue determination of benzimidazoles in beef liver and muscle: collaborative study. Journal of the Association of Official Analytical Chemists, 74 (3) 487-493.

28. Nerenberg, C., Runkel, R. A., Matin, S. B. (1978). Radioimmunoassay of oxfendazole in bovine, equine, or canine plasma or serum. Pharmaceutical Sciences, 67 (11) 1553-1557.

29. Dinc, E., Onur, F. (1997). Comparative study of the ratio spectra derivative spectrophotometry, derivative spectrophotometry and Vierordt's method applied to the analysis of oxfendazole and oxyclozanide in a veterinary formulation. Analusis, 25 (3) 55-59.

30. Dinç, E., Kanbur, M. (2002). Spectrophotometric multicomponent resolution of a veterinary formulation containing oxfendazole and oxyclozanide by multivariate calibration-prediction techniques. Journal of Pharmaceutical and Biomedical Analysis, 28 (3-4) 779-788.

31. Dinç, E., Băleanu D. (2007) Continuous wavelet transform applied to the overlapping absorption signals and their ratio signals for the quantitative resolution of mixture of oxfendazole and oxyclozanide in bolus. Journal of Food and Drug Analysis, 15 (2) 109-117.

32. European Pharmacopoeia (1997), 3rd Edition, Council of Europe, France, p. 55.

33. United States Pharmacopoiea (2008) 32-NF27, pp. 3155.

34. International Conference on Hormonisation of Technical Requirements for Registration of Pharmaceuticals for Human Use, ICH Harmonised Tripartite Guideline, Validation of Analytical Procedures: Text and Methodology Q2(R 1), Complementary Guideline on Methodology dated 06 November 1996, incorporated in November 2005, London.

35. Jiri Kucharski, R. N., Safarik, L. (1965). Titrations In Non-Aqueous Solvents”. 1th Ed, Elsevier Publishing Company, Amsterdam-London-New York, p. 94.

36. Miller, J. N., Miller J.C. (2000). Statistics and Chemometrics for Analytical Chemistry, 4th Ed, Pearson Education Limited, England. 